\title{
Intra-Firm Spillovers? The Stock and Flow Effects of Collocation
}

by

\author{
Evan Rawley \\ Columbia University
}

\author{
Robert Seamans \\ New York University
}

\section{CES 15-01 January, 2015}

The research program of the Center for Economic Studies (CES) produces a wide range of economic analyses to improve the statistical programs of the U.S. Census Bureau. Many of these analyses take the form of CES research papers. The papers have not undergone the review accorded Census Bureau publications and no endorsement should be inferred. Any opinions and conclusions expressed herein are those of the author(s) and do not necessarily represent the views of the U.S. Census Bureau. All results have been reviewed to ensure that no confidential information is disclosed. Republication in whole or part must be cleared with the authors.

To obtain information about the series, see www.census.gov/ces or contact Fariha Kamal, Editor, Discussion Papers, U.S. Census Bureau, Center for Economic Studies 2K132B, 4600 Silver Hill Road, Washington, DC 20233, CES.Papers.List@census.gov. 


\begin{abstract}
We examine the impact of collocation on local within-firm performance, or intra-firm spillovers, by decomposing spillovers into one-time stock and recurring flow effects. Stock effects include one-time learning effects. Flow effects include ongoing resource sharing as well as cannibalization. Using data on the population of U.S. hotels and restaurants from 1977-2007, we exploit changes in the number of collocated establishments owned by the same firm to estimate the relative importance of stock and flow benefits. We find that collocation improves the productivity of new and existing establishments by 1-2\%, even when correcting for endogenous orting into collocation. The results, in conjunction with our field work, suggest that collocation generally facilitates the transfer of knowledge within the firm, but that flow effects of collocation are more sensitive to the broader economic environment.
\end{abstract}

\footnotetext{
* Rawley: Columbia Business School (email: erawley@columbia.edu); Seamans: Stern School of Business, New York University (email:rseamans@stern.nyu.edu).Weare grateful to Janet Bercovitz, Ha Hoang, Arturs Kalnins, Jenny Kuan, Joanne Oxley, Arvids Ziedonis, Rosemarie Ziedonis, seminar participants at BI Norwegian Business School, Copenhagen Business School, ESMT, NYU Stern School of Business, and conference participants at the 2014 Strategic Management Society Annual Conference and 2014 Kauffman Emerging Scholars Conference for valuable comments and suggestions. The res earch in this paper was conducted while the authors were Census Bureau research associates at the New York City Census Research Data Center (NYCRDC). Research results and conclusions expressed are our own and do not necessarily indicate concurrence by the Bureau of Census. This paper has been screened to insure that no confidential data are revealed. Financial support for this work was provided to Seamans by the Ewing Marion Kauffman Foundation. The contents of this publication are solely the responsibility of the authors.
} 
Intra-firm spillovers? Evidence from stock and flow effects

\section{INTRODUCTION}

Multi-unit firms in many industries engage in collocation whereby they open new units in close geographical proximity to their pre-existing units. What effect does such collocation have on multiunit firms' performance? The potential benefits include knowledge sharing (Darr, Argote and Epple, 1995), economies of scope through referral making (Baum and Ingram, 1988) or resource sharing (Alcacer, 2006; Chung and Kalnins, 2001; Kalnins and Chung, 2004; McCann and Vroom, 2010) and improved performance via better monitoring and benchmarking (Giroud, 2013; Lu and Wedig, 2013). The potential costs include cannibalization of existing unit sales (Kalnins, 2004; Bennett, Seamans and Zhu, forthcoming). Moreover, resource sharing also creates coordination and overhead costs (Williamson, 2005; Rawley, 2010; Zhou, 2011).

Yet, in spite of the great strides scholars have made in this area, we still know little about the persistence and direction of collocation effects — whether the benefits are primarily derived from stock effects (e.g., one-time learning) or from more transitory flow effects (e.g., ongoing resource sharing); and whether collocation primarily benefits new establishments, existing establishments or both—which can have tremendously different implications for strategy. One potential reason we still have these gaps is that it is usually difficult to examine establishmentlevel performance with precision. A second reason is the fundamental endogeneity of the choice to collocate (Jaffe, Trajenberg and Henderson, 1993; Ellison, Glaeser and Kerr, 2010).

In this paper we take a step toward disentangling the effects of collocation on performance using broad and rich microdata from two key industries where multiunit firms play a major role — the U.S. hotel and restaurant industries 1977-2007—which we use to disentangle persistence and direction of effects in collocated firms. Using this data we make several contributions. First, we document a positive relationship between intra-firm collocation and 
productivity. We find that collocation improves the productivity of new and existing establishments by $1-2 \%$. After correcting for endogeneity, these results appear closer to $2 \%{ }^{1}$ Second, we demonstrate theoretically and empirically how the use of entry and exit of collocated establishments can be used to disentangle the stock versus flow effects of collocation. Finally, using this approach, we show that the stock benefits are large and consistent across industries, suggesting that collocation facilitates the transfer of knowledge across establishments in two ways: (i) new establishments gain local knowledge from existing establishments and (ii) new establishments act as laboratories, experimenting with new approaches and techniques, and then transferring that knowledge back to existing establishments. By contrast flow effects are positive in the hotel industry, but negative in the restaurant industry, suggesting that the cost of cannibalization from collocation can outweigh resource sharing benefits, based on the particulars of the institutional environment. ${ }^{2}$

Our analysis is particularly compelling for three reasons. First, the context is economically important: the U.S. accommodation and food service industries generated approximately $\$ 450 \mathrm{~B}$ in sales in $2002 .^{3}$ More broadly, the travel and tourism industry accounts for close to $3 \%$ of world GDP. ${ }^{4}$ Second, we can measure hotel and restaurant performance effects at an unusual level of precision as we have detailed establishment-level financial data on a complete census of every hotel and restaurant establishment ever operated (for at least five years) in the United States 1977-2007. Third, our research design exploits the richness and

\footnotetext{
${ }^{1}$ To put these results in context, Giroud (2013) finds that decreases in monitoring costs of establishments leads to productivity increases of $1.3-1.4 \%$

${ }^{2}$ The food service business (NAICS code 722) is more competitive than the accommodation business (NAICS code 721). The 4 largest food service firms account for $5.7 \%$ of sales, whereas the 4 largest accommodation firms account for $16.8 \%$ of sales. Source: US Census Bureau "Establishment and Firm Size: 2002" Available: https://www.census.gov/prod/ec02/ec0272sssz.pdf, last accessed August 29, 2014.

${ }^{3}$ Accommodation and food service are both classified under NAICS code 72. US Census Bureau "Establishment and Firm Size: 2002" Available: https://www.census.gov/prod/ec02/ec0272sssz.pdf, last accessed August 29, 2014.

${ }^{4}$ http://www.wttc.org/site_media/uploads/downloads/world2012.pdf
} 
breadth of the data to deliver plausibly causal estimates of the magnitude of learning effects and the benefits of resource sharing net of coordination costs, as well as providing some insight into the mechanisms behind these effects. Specifically, we employ a differences-in-differences estimator with establishment and time fixed effects and market-specific time trends, which is robust to matching both treated to non-treated legacy establishments and new establishments to jettisoned establishments. We also show our results are robust to alternative explanations, including those that center on competition (e.g., Baum and Haveman, 1997), referrals (Baum and Ingram, 1988) and franchising (e.g., Kalnins, 2004; Kalnins and Lafontaine, 2014).

\section{THEORY AND LITERATURE}

We build off of and contribute to several streams of literature. It is useful to position this literature in the context of the $2 \times 2$ matrix depicted in Figure 1 that differentiates between flow and stock effects of collocation, and whether the effects are due to inter-firm or intra-firm spillovers. These spillovers can be further categorized as benefits or costs to the focal firm or establishment.

Quadrant I describes ongoing spillovers that accrue across firms due to geographical clustering. We think of these types of spillovers as "flow" spillovers in that they recur period after period, rather than occurring one time. The positive spillovers or benefits can be thought of as classic agglomeration spillovers described by Marshall (1920/1890). Examples of such spillovers include complementary demand whereby increased clustering drives customer traffic, which may in turn allow incumbent establishments to increase prices (e.g., Chung and Kalnins, 2001; McCann and Vroom, 2010), and complementary supply whereby increased clustering attracts specialized suppliers of resources (e.g., Jaffe, Trajenberg, and Henderson, 1993; Saxenian, 1994). The negative spillovers or costs can be thought of as classic negative spillovers 
from increased competition for customers or resources, leading either to lower prices, as in standard Bertrand competition models, or increased costs due to a reduction in bargaining power with suppliers (e.g., Brandenburger and Stuart, 2007).

Quadrant II describes flow spillovers in an intra-firm setting. These are not classical spillovers from one firm to another, but rather spillovers (or "spill - ins") that accrue to sister establishments owned by the same parent firm in close proximity to each other. Benefits include increased economics of scale in purchasing and branding (Jin and Leslie, 2009), enhanced monitoring ( $\mathrm{Lu}$ and Wedig, 2013; Kalnins and LaFontaine, 2014), and ongoing learning and benchmarking (Baum and Ingram, 1998; Kalnins \& Mayer, 2004). Costs include cannibalization in that different business units owned by the same parent firm are now competing for the same customers (Kalnins, 2004; Pancras, Sriram, and Kumar, 2012).

Quadrant III describes one time spillovers from one firm to another due to geographical clustering. We think of these types of spillovers as "stock" spillovers in that they occur one time, rather than period after period. These types of spillovers typically involve knowledge, for example of a production technique or technological capability (Mowery, Oxley, Silverman, 1996), but in principle could involve human as well as intellectual capital (Allen, 1984). A firm with valuable knowledge gains a competitive advantage over its rivals, but loses this advantage if the knowledge leaks from its firm to a "pool" of localized knowledge accessible by its rivals. An open question in this literature is the extent to which incumbents and entrants can equally benefit from these pools of knowledge or whether the effects are asymmetric in that entrants and incumbents benefit differentially from each other (Eeckhout and Jovanovic, 2002; Knott, Posen and $\mathrm{Wu}, 2009$; Posen and Chen, 2013). Given the potentially large gains from such knowledge spillovers, firms engage in costly mechanisms to imitate, if they are the "lagging" firm, or to 
deter imitation, if they are the "leading" firm. One reason the cost of imitation is high is the "casual ambiguity" of the leading firm's enhanced performance (Ethiraj, Levinthal, Roy, 2008; Ryall, 2009).

Quadrant IV describes stock spillovers in an intra-firm setting. These benefits occur when a sister unit transfers some valuable knowledge to other units owned by the same parent firm in the same geographic area. It is important to point out that our focus is on one time, intra-firm spillovers that accrue because of local agglomeration. This is in contrast to existing literature which studies the spread of knowledge across all business units, regardless of location (e.g., Darr, Argote and Epple, 1995). This is also in contrast to international business literature which studies the ways in which multi-national corporations transmit knowledge gained in one country to business units in other countries (e.g., Bresman, Birkinshaw and Nobel, 1999; Gupta \& Govindarajan, 2000). While firms can benefit from sharing useful knowledge between sub-units, there are many potential costs including coordination, bureaucratization and internal politicking (Williamson, 2005; Rawley, 2010; Zhou, 2011). Unlike with inter-firm spillovers, however, there should be less causal ambiguity.

Our paper builds on and contributes to this existing literature in several ways. Our first contribution is to document that intra-firm spillovers arising from collocation (Quadrants II and IV) lead to performance improvements. These performance improvements are net of any interfirm spillovers (Quadrants I and III), which we control for in our regressions. Second, to the best of our knowledge, we are the first to study the relative contribution of stock and flow effects of intra-firm collocation on performance (comparing Quadrants II and IV). Third, we compare the effect of intra-firm collocation on performance for incumbent establishments and entering establishments. To the best of our knowledge, existing literature has focused solely on these 
differences in an inter-firm setting. We find that collocated incumbent and entrant establishments receive similar benefits, after correcting for selection. This suggests that the "pools" of localized knowledge gained over time by the establishments in our setting are readily accessed by the firms' other establishments in the same locale.

\section{RECOVERING STOCK AND FLOW EFFECTS}

Before turning to our empirical tests we show how one can exploit positive and negative collocation events to separate stock and flow effects. Suppose an establishment's performance $\pi$ is a function of its initial endowment $\pi_{0}$ plus the benefits B and (positive) costs $\mathrm{C}$ of collocation, and a mean zero random disturbance term $e$. If the benefits of collocation arrive as a one-time persistent stock benefit, $\bar{a}>0$, and as a flow benefit $b_{t+n}>0$ that persists during the $n$ periods the establishment is collocated, then we have:

$$
\pi_{t}=\pi_{0}+B_{t}-C_{t}+e_{t}=\pi_{0}+\bar{a}+b_{t}-C_{t}+e_{t}{ }^{5}
$$

Therefore, if the establishment becomes collocated at time $t$ due to the arrival of another establishment in the same market from the same firm, the expected change in performance is:

$$
E\left(\Delta^{+} \pi\right)=\bar{a}+b_{t}-C_{t},
$$

where there are net benefits to collocation when $\bar{a}+b_{t}>C_{t}$. By contrast, if the collocated counterparty to the establishment is subsequently eliminated, say at time $t+1$, the expected

\footnotetext{
${ }^{5}$ Given expression (1), changes in performance for the establishment due to a change in its collocation status can be written as changes in the costs and benefits of collocation: $\Delta \pi=\Delta \bar{a}+\Delta b-\Delta C+\Delta e$.
} 
change in performance is:

$$
E\left(\Delta^{-} \pi\right)=b_{t+1}-b_{t}-\left(C_{t+1}-C_{t}\right)=C_{t}-b_{t},
$$

where there is a reduction in the flow benefits due to colocation when $C_{t}<b_{t}$.

Using expressions (2) and (3) together we can recover the stock benefit of colocation by subtracting the change in performance from a negative colocation event from a positive colocation event:

(4) $\quad E\left(\Delta^{+} \pi\right)-E\left(\Delta^{-} \pi\right)=\bar{a}$.

Below, we use the empirical analog of (4) to establish the magnitude and direction of the stock of knowledge that is transferred when establishments co-locate, and the empirical analog of (3) to establish the flow benefits of resource sharing due to collocation in the hotel industry. Note that in cases where cannibalization or other flow costs are relatively high, such as in the restaurant industry (Pancras, Sriram, and Kumar, 2012; Quelch, 2008), that we will find there to be negative flow effects; that is, $b_{t+n}<0$.

\section{DATA AND EMPIRICAL STRATEGY}

\subsection{Data}

We obtain establishment level data from the US hotel and restaurant industries from the 19772007 quinquennial Economic Census of Services and Economic Census of Retail Trade. They 
include the revenue and payroll of every hotel and restaurant in the United States, tracked longitudinally with a unique identifier, along with location and firm identifiers. ${ }^{6}$ Most establishments in the Economic Census are surveyed directly by the Census Bureau, though data are imputed for some establishments with few employees. We exclude establishments for which data has been imputed along with other unusual observations-establishments that are in the smallest $10 \%$ of the size distribution (by revenue) and observations in the $1^{\text {st }}$ and $99^{\text {th }}$ percentile of the labor factor productivity distribution. ${ }^{7}$

We define a market to be a metropolitan statistical area (MSA). This definition of a market represents an imperfect compromise between defining markets as areas large enough to pick up the knowledge-based "stock" collocation effects that we are particularly interested in, while small enough to meaningfully capture a local area. Other studies of collocation in the hotel and restaurant industries have used other, smaller market definitions, particularly when the studies focused on micro-market "flow" collocation effects, such as referrals or physical asset sharing. Our MSA-based market definition would also capture these effects, but would tend to underestimate their average effect compared to stock effects. We verify that all of the key results hold using counties, which are typically substantially smaller than MSAs, as our market definition.

For the analyses described below, we use four data sets: two from the hotel industry and two from the restaurant industry. For our main sets of results on incumbent performance, we focus on within-establishment changes in productivity from collocation. Observations that

\footnotetext{
${ }^{6}$ The biggest advantage of studying hotels using Economic Census data over using the dataset from Smith Travelthe most commonly used dataset for analyzing the hotel industry - is that the Economic Census provides data on revenues and payroll so that one can estimate productivity effects. The Economic Census is also more complete, as it contains every hotel in the United States, while Smith Travel only has data on larger chain hotels. On the other hand the Smith Travel dataset has information on occupancy rates and brands, which the Economic Census lacks. ${ }^{7}$ Labor factor productivity is measured as the residual from a pooled OLS regression of log revenue on log payroll with year fixed effects.
} 
appear only once in the panel, those outside of metropolitan statistical areas, and establishments that are local monopolies are excluded, though the results are not sensitive to including these observations. The resulting dataset used for the main set of hotel results contains 58,648 hotels and 180,583 hotel-years from 23,985 firms. The resulting dataset used for the main set of restaurant results contains 313,609 restaurants and 856,599 restaurant-years from 146,416 firms. Summary statistics on these datasets, which we refer to as the "incumbent datasets" below, are presented in Table 1.

An additional set of results on entrant performance is generated by comparing the productivity of new establishments that are collocated with an incumbent to new establishments owned by the same firm that are not collocated. We use observations from 1977 to establish a baseline of incumbents in a market. We then create a dataset of establishments that enter at any point from 1982 - 2007. These establishments remain in the dataset for the year of entry and all subsequent years until 2007 or the establishment exits, whichever comes first. As with the incumbent dataset, we exclude establishments located outside of metropolitan statistical areas (MSA), and local monopolies. The resulting datasets contains 261,906 hotel-years and 1,459,118 restaurant-years. Summary statistics for these datasets, which we refer to as the "entrant datasets" below, are presented in Table $2 .^{8}$

\subsection{Effect of collocation on incumbent establishments}

In our baseline tests we estimate the impact of collocation on productivity using a differences-indifferences estimator on the full panel. Specifically, for establishment $i$ in year $t$ we regress $\log$

\footnotetext{
${ }^{8}$ There are fewer observations in the incumbent datasets than in the entrant datasets, due to the restriction in the incumbent datasets that there be two or more observations for an establishment, which is necessary given the use of establishment fixed-effects in our estimating equation.
} 
revenue, $y$, on log payroll, $l$, the $\log$ of the number of establishments from the same firm in the same market (e.g., MSA), ESTABS, with establishment, $\lambda$, and year, $T$, fixed effects and vector of controls $\boldsymbol{X}_{\boldsymbol{c}}$ :

$$
y_{i t}=\alpha+\beta_{l} l_{i t}+\beta_{1} \text { ESTABS }_{i g t}+\lambda_{i}+\boldsymbol{T}_{t}+\boldsymbol{X}_{c i t} \boldsymbol{B}_{c}+\varepsilon_{i t}
$$

The vector $\boldsymbol{X}$ controls for changes in local supply and demand conditions, and contains variables that proxy for other potential shocks to an establishment's production function, including: log establishment age-measured as the difference between the observation year and the year in which the establishment was first captured in the Economic Census, the log of the count of competitors' establishments in the same market, the average labor factor productivity of other establishments in the same market, an ownership change dummy that is equal to one when the focal establishment reports being owned by a different entity at time $t$ compared to time $t-1$ and zero otherwise, the log of the number of establishments owned by the same firm in other markets (plus one), and in the most demanding specification, hundreds of market-year fixed effects. All dollar-denominated values are deflated to 1977 dollars using CPI deflators from the Bureau of Labor Statistics. $\varepsilon_{i t}$ is a mean-zero, normally distributed error term. Standard errors are clustered at the establishment-level.

Expression (5) decomposes labor factor productivity into an establishment-specific component, and a component due to collocation. Given the log-log specification, the coefficient on $E S T A B S_{i g t}$ can be interpreted as an elasticity, which captures the percentage change in labor factor productivity in response to a percentage change in the intensity of collocation. Furthermore, because the expression includes establishment-level fixed effects that controls for 
an establishments average capital stock, one can interpret the effect of collocation effect (5) as approximating a total factor productivity effect, as long as changes in capital stock are roughly proportional to changes in labor and the control variables, and are not correlated with the collocation decision.

Brand information is not reported consistently to the Census Bureau so our estimate of the effect of collocation should be interpreted as firm-level, not brand-level, collocation effects, a data limitation that will tend to bias our results toward zero. Since hotels and restaurants are often franchised, the absence of brand information means that there will be markets where two establishments of the same brand (e.g., Marriott hotels) are collocated but are owned by two different franchisees. To the extent that brand collocation effects are meaningful, our results will underestimate "true" collocation effects in two ways. First, by confining our measure of such effects only to within-firm collocation we will miss positive collocation effects that operate at the brand, but not the firm-level. Second, by comparing firm collocation effects against establishments that benefit from brand collocation effects we overestimate the baseline against which firm collocation effects are measured, and therefore underestimate firm collocation effects (i.e., because we have a differences-in-differences specification). While we would rather capture both firm and brand-level collocation effects, the former appears to be understudied in the literature, and yet one might expect within-firm collocation effects to be quite important, even when a firm operates multiple brands.

\subsection{Effect of collocation on entrant establishments}

We also study the effect of collocation on productivity of the entering establishments. For establishment $i$ in year $t$ we regress $\log$ revenue, $y$, on $\log$ payroll, $l$, the log of the number of 
establishments from the same firm in the same market (e.g., MSA), ESTABS, with fim, $\delta$, and year, $T$, fixed effects and vector of controls $\boldsymbol{X}_{\boldsymbol{c}}$ :

$$
y_{i t}=\alpha+\beta_{l} l_{i t}+\beta_{1} E S T A B S_{i g t}+\delta_{g}+\boldsymbol{T}_{t}+\boldsymbol{X}_{c i t} \boldsymbol{B}_{\boldsymbol{c}}+\varepsilon_{i t}
$$

The vector $\boldsymbol{X}$ controls for changes in local supply and demand conditions, and contains variables that proxy for other potential shocks to an establishment's production function as in (5) above. $\varepsilon_{i t}$ is a mean-zero, normally distributed error term. Standard errors are clustered at the establishment-level.

\subsection{Learning and resource sharing effects of collocation}

Specification (5) is useful for demonstrating a positive correlation between collocation and performance, but is subject to two limitations. First, it does not allow one to separately identify the stock ("learning") and flow ("resource sharing") effects of collocation because $\beta_{1}$ does not distinguish between positive and negative changes in the intensity of collocation — when $\beta_{1}>0$ all we can infer is that collocation improves with (or is correlated with) performance.

Second, one can only interpret the coefficient on $E S T A B S_{i g t}$ as the causal effect of collocation on productivity if there are no omitted variables in specification (5) that are correlated with the dependent variable (log revenue) and the error term. In other words, the identifying assumption is there are no unobservable factors missing in specification (5) that would both increase (decrease) revenue for the focal establishment and increase (decrease) the establishment's intensity of collocation. While it seems plausible that $\beta_{1}$ is well identified in specification (5) - it controls for time-invariant establishment-specific factors, macro-economic 
trends, changes in local market supply and demand conditions, and firm size and productivity—it does not control for heterogeneity in selection process by which firms choose markets in which to add a new establishment or eliminate an existing one.

We deal with the key measurement and identification issues in turn. First, to disentangle the effects of learning and resource sharing (net of coordination costs) we discretize changes in collocation intensity into positive and negative categorical variables and study the asymmetries between these two effects, using:

$$
y_{i t}=\alpha+\beta_{l} l_{i t}+\beta_{p o s} \mathrm{COLO}+_{i t}+\beta_{n e g} \mathrm{COLO}-_{i t}+\lambda_{i}+\boldsymbol{T}_{\boldsymbol{t}}+\boldsymbol{X}_{c i t} \boldsymbol{B}_{\boldsymbol{c}}+\varepsilon_{i t}
$$

where $C O L O+$ and $C O L O$ - are categorical variables that are equal to one when the firm adds or removes an establishment from an existing market where it had/retains a presence, respectively, and are zero otherwise. $\beta_{\text {pos }}$ captures positive collocation effects, including both learning and net resource sharing effects. Negative collocation effects, captured by $\beta_{n e g}$, however, only pick up a reduction in the net resource sharing effects of collocation, as any learning stock effects, by definition, would have already been absorbed into the production functions of the remaining establishments in the local market. Thus, by comparing the coefficient estimates on positive and negative collocation we can recover learning and net resource sharing effects of collocation on productivity: flow benefits of collocation $=-\beta_{\text {neg }}$, stock benefits of collocation $=\beta_{\text {pos }}+\beta_{\text {neg. }}{ }^{9}$

To deal with the endogeneity of firm's collocation decisions, we use propensity score matching and Coarsened Exact Matching (CEM) to identify "control group" establishments that are similar to establishments in firms and markets where collocation changes. Specifically, with

\footnotetext{
${ }^{9}$ Since census data is collected every five years, stock benefits are measured over approximately 2.5 years.
} 
propensity score matching we specify a logit predicting a positive change in collocation, and a logit predicting a negative change in collocation:

$$
C O L O_{+i t}=f\left(l_{i t-1}, \boldsymbol{T}_{\boldsymbol{t}}, \boldsymbol{X}_{\text {cit-1 }}\right),
$$

$$
C O L O_{-i t}=f\left(l_{i t-1}, T_{t}, X_{c i t-1}\right)
$$

where $\boldsymbol{X}_{\text {cit-1 }}$ includes all of the controls from (1) and (2) lagged one period (i.e. 5 years, given the nature of the Census data) except the market-year fixed effects. ${ }^{10}$ The logits establish the propensity score for existing establishments of the probability of receiving a "treatment," where the propensity score summarizes all of the available observable information about the selection process by which establishments are sorted into treatment and control groups. Using the common support of the propensity score distributions - the predicted values for treatment and control group observations from (3) and (4) —after trimming off outliers, we match non-treated establishments one-to-one to treated establishments. ${ }^{11}$

We also match positive and negative treatments to two sets of control group observations using the Coarsened Exact Matching (CEM) technique developed by Iacus, King and Porro (2011, 2012). CEM is conceptually similar to propensity score matching in that it matches treated observations to "similar" control group observations based on all observable characteristics of both. However, instead of matching observations based propensity scores, CEM matches exactly on a bundle of discretized characteristics, which typically makes the procedure substantially more efficient computationally than propensity score matching. Another key difference between the two approaches is that CEM eliminates the need for "balance

\footnotetext{
${ }^{10}$ Including 362 additional market-year dummy variables in the logits increase processing time dramatically, but does not have a meaningful impact on the results.

${ }^{11}$ We obtain similar results if we allow multiple matches per treated observation.
} 
checking"; that is, because CEM matches exactly, one need not ensure that the mean of the distribution of each variable in the matching algorithm is similar after matching, as in propensity score matching. Since each observation matches exactly along all observable dimensions we care much less about the exact distribution of the covariates. While eliminating balance checking has certain advantages, namely it eliminates ad hoc decisions about where to cut outliers, it is not a panacea, as it is not necessarily conceptually obvious how much to coarsen the data without balance checking the result afterward to see if the variables have been coarsened "enough."

The two samples (e.g., from (8) and (9)) are then combined and analyzed using specifications (5) and (7). If the remaining unobservable establishment-specific time-varying information does not affect both the collocation selection process and changes in revenue at the focal establishments, then the matched sample will approximate random assignment of collocation events to legacy establishments. That is, if the matched sample represents a valid counterfactual to the treatment group observations, one can interpret of the coefficients on the collocation as average causal effects of collocation.

\section{RESULTS}

\subsection{Summary statistics}

Summary statistics for the incumbent and entrant datasets are presented in Tables 1 and 2, respectively. First focusing on the incumbent dataset (Table 1), we note that $\log$ establishments $_{j g t}$ is 1.64 . This means that the average incumbent hotel is collocated with approximately 5 other sister hotels (i.e., those owned by the same parent firm) in the MSA. Note also that Log $_{\text {establishments }}^{j-g t}$ is 0.61 , meaning that the average incumbent hotel has 
approximately two sister hotels located in other MSAs. It is interesting to contrast these numbers with those for restaurants. For restaurants Log establishments jgt $_{\text {is }}$ 0.67. This means that the average incumbent restaurant is collocated with approximately 2 other sister restaurants (i.e., those owned by the same parent firm) in the MSA. Log establishments j-gt $_{\text {is }}$ is 1.18 , meaning that the average incumbent restaurant has approximately three sister restaurants located in other MSAs. Thus, there appears to be more clustering in the hotel than the restaurant industry. Second, it is also interesting to compare the positive treatment and negative treatment dummies across the two industries. The averages for hotels are 0.02 and 0.01 , respectively. The averages for restaurants are 0.07 and 0.06 , respectively. Thus, there are more entries and exits, or higher churn, in the restaurant industry.

\subsection{Baseline results for incumbents and entrants}

Table 3 presents the baseline results corresponding to equation (5) above. This set of regressions investigates the effect of within-establishment changes in collocation on establishment performance. In Column 1, Log sales $_{j g t}$ is regressed against Log establishments jgt $_{1}$, Log $_{\text {payroll }}$ jgt and establishment and year fixed effects. The coefficient on Log establishments jgt $_{\text {is }}$ positive and significant, indicating that an increase in collocation leads to better performance. Column 2 includes additional controls for age, number of other establishments in the MSA, average productivity across the other establishments in the MSA, number of other establishments owned by the same firm in other MSAs, an ownership change dummy, dummies for establishment owner performance quartile, and MSA-year fixed effects. The coefficient on $\log$ establishments $_{\text {jgt }}$ remains positive, significant, and of similar magnitude. Columns 3 and 4 replicate the prior set of regressions on restaurants. The coefficient on Log establishments jgt $_{\text {for }}$ 
restaurants is also positive and significant, though of lower magnitude than that for hotels. This difference may owe to multiple factors, including that increases and decreases of collocated establishments have different effects on restaurants than on hotels, and that the sample characteristics differ across hotels and restaurants. These issues will be addressed in greater detail below. The results from Table 3 therefore provide initial evidence of positive spillovers arising from intra firm collocation.

In Table 4 we present results on the "entrant" dataset, with results corresponding to equation (6) above. This set of regressions compares the performance of entering establishments that are collocated to entering establishments that are not collocated. In Column 1, Log sales jgt $_{\text {is }}$ regressed against a dummy indicating if the establishment is a Collocated establishment ${ }_{i t}$, Log payroll $_{j g}$, and number of controls including year fixed effects. The coefficient on the dummy Collocated establishment $t_{i t}$ is positive and significant, indicating that entering establishments that enter nearby another establishment owned by the same firm performs better than entering establishments that are not. Column 2 includes a firm fixed effect. The coefficient on the dummy Collocated establishment $t_{i t}$ remains positive and significant, though the magnitude of the coefficient drops by close to 50\%, indicating a substantial amount of heterogeneity across firms in terms of their decision about whether and when to co-locate. Columns 3 and 4 replicate the prior set of regressions on restaurants. The coefficient on Collocated establishment ${ }_{i t}$ for restaurants is also positive and significant, and of similar magnitude as for hotels.

\subsection{Disentangling stock and flow effects of collocation}

We next work to disentangle stock and flow effects of collocation. To do this, we discretize changes in collocation intensity (Log establishments jgt $_{\text {) }}$ into positive and negative categorical 
variables and study the asymmetries between these two effects. Table 5 presents the results corresponding to equation (7) above. In Column 1, Log sales jgt $_{\text {is }}$ regressed against Positive treatment and Negative treatment, as well as Log payroll jgt $_{\text {and }}$ a full set of controls including establishment and year fixed effects, but excluding MSA-Year fixed effects. Column 2 replicates this regression, and also includes MSA-Year fixed effects. We find that positive treatment has a positive and statistically significant effect on collocation of $3.3 \%$, that negative treatment has a negative and statistically significant effect on collocation of $-1.4 \%$. The difference in magnitude between the two, 1.8\%, the stock effect, is also statistically significant. In other words, an incumbent establishment experiences a productivity increase when its parent opens a new establishment in close proximity, but the productivity decrease when the parent closes an establishment in close proximity is less in absolute value. This suggests that just over half of the benefit of collocation is associated with stock benefits, such as one-time learning effects, and just under half is associated with flow benefits.

We perform the same tests on the restaurant sample presented in columns 3 and 4 . We find a positive treatment effect of $2.8 \%$ for restaurants, which is similar in direction and magnitude to the effect for hotels. However, we find a negative treatment effect of $1.1 \%$ for restaurants, which is the opposite direction than for hotels. This result suggests that restaurants benefit when a nearby restaurant owned by the same firm is added or removed. The interpretation is that, absent meaningful selection effects, cannibalization and other flow costs exceed the flow benefits of collocation, such that stock effects are actually $40 \%$ larger than the net benefit of collocation.

\subsection{Addressing threats to identification}


While our baseline results suggest a positive relationship between collocation and performance, it is possible that this specification suffers from endogeneity. The ideal experiment would be one in which collocation is randomly varied across focal establishments. Unfortunately, it is not feasible to run such an experiment, and moreover it is certainly reasonable to expect that firms carefully consider where and when to open a new establishment (Shaver and Flyer 2000). For example, it is likely that firms consider future growth in a region when opening a new hotel or restaurant establishment, which is why the regressions with the MSA-Year fixed effects are so important. Identification in these specifications comes from variation in collocation of establishments in the same MSA-Year. These results effectively control for any region-year specific idiosyncrasies, such as unobserved changes in demand.

In order to further address endogeneity concerns, we next turn to a matching approach as described in Section 4.4. Table 6 presents the analyses of our base matching processes. The table shows that the propensity score matching approach was successful for the hotel sample. Column (1) provides t-tests of differences of means between treated and control observations from the sample we use to estimate equation (5) for hotels. Column (2) provides t-tests of differences of means between treated and control observations after eliminating observations that were off the common support of the joint distribution of the propensity scores for positive and negative treatment groups separately, trimming off outliers at the $25^{\text {th }}$ and $95^{\text {th }}$ percentile of the joint propensity score distribution, and restricting observations to the one-one matched sample. Per Census Bureau disclosure restrictions we report only whether the differences in the means were positive or negative and whether they were significant at the $5 \%$ or $10 \%$ level. Comparing t-tests across the two columns, we note that the matching algorithm results in a substantial reduction in the difference in means. Whereas the t-tests were significant in all cases before 
matching, after matching, only log establishments, and the MSA labor factor productivity remains significantly different; and the latter is only significant at the $10 \%$ level. We obtained similar "second stage" results using Coarsened Exact Matching, though the covariates did not balance as closely as in the propensity score specification. Unfortunately we could not obtain high quality matches using propensity score matching with the restaurant sample, in that we could not find matches where most of the differences in the means of the covariates were not statistically significant between the treatment and control group. We therefore cannot claim that our second stage propensity score matched results are meaningful for the restaurant sample, and instead report only the CEM results.

Table 7 presents the matched sample results. Column (1) is similar to the regression from Table 3 Column (2) for hotels, but using only the propensity score matched sample. ${ }^{12}$ The magnitude of the coefficients on Log establishments ${ }_{j g t}$ are similar across both tables, suggesting that selection on observables does not have a large impact on the magnitude of local within firm collocation effects. The CEM results were similar in terms of sign, significance and economic magnitude. Column (2) performs the same for restaurants using the CEM matched sample. The coefficient on Log establishments L $_{g t}$ is approximately $1.9 \%$ in the matched sample analysis compared to $1.1 \%$ in the unmatched sample, suggesting that selection has a large bearing on overall collocation effects in the case of restaurants.

Nevertheless, in both the hotel and restaurant samples, collocation appears to have a meaningful positive causal effect on local within-firm performance. In other words, it appears that intra-firm spillovers are indeed economically and statistically significant. While we cannot be certain that selection on unobservables is not biasing the results, for example time-varying

\footnotetext{
${ }^{12}$ Because the matched sample is only $7 \%$ of the overall hotel sample, a number of MSAs have only a single observation in each period. As such, we exclude the MSA x year fixed effects in this specification, though including them has no meaningful effect on the main result.
} 
establishment-specific ability to exploit collocation benefits, the richness of the data, and the nature of the statistical tests (e.g., establishment fixed effects), suggests that unobservables are unlikely to play a large role in our particular context.

\subsection{Discussion}

The results suggest that intra-firm collocation has a causal effect on establishment level productivity. We interpret this effect as evidence of intra-firm spillovers in the sense that randomly assigning collocation to an existing establishment leads to increased productivity. However, we do not wish to suggest that intra-firm spillovers are externalities, as with inter-firm spillovers. Indeed, once the intra-firm collocation decision has been made, we expect firms to endogenously work hard to find the benefits of collocation and minimize the costs. Whereas, with inter-firm collocation, we expect just the opposite: firms will react to collocation by other firms by seeking ways to minimize the benefits that flow to others. Thus, intra-firm spillovers are related to, but different than inter-firm spillovers. Both refer to the causal effects of collocation, but only the latter are externalities with broad social implications.

The potential for unobservable changes in capital stock to confound the collocation effect we estimate represents the main limitation of our empirical approach. If firms typically refurbish their existing establishments when they collocate another establishment in the same area, we would conflate productivity effects with factor intensity effects. While our interviews with hotel executives suggested that such investment patterns would by no means be the norm-hotel firms do not generally upgrade a legacy establishment when they open a new one, but rather choose to reinvest in hotels in attractive areas whether or not they collocate in those areas-we cannot completely rule out the potential for such effects to be at work. However, our matching 
approach does address this issue to some extent, as one would expect that if reinvestment rates were higher in collocated hotels, they would also be higher for hotels with similar ex ante characteristics that were not "treated" with collocation.

Our matching approach itself does have limitations, however. Because we can only match on observables, unobservables that are uncorrelated with our controls, but correlated with collocation still represent a potential endogeneity concern. Moreover, empirically we could not identify a strong matched sample in the restaurant data using propensity score matching. While our alternative Coarsened Exact Matching approach is conceptually sound, the failure of propensity score matching to find a similar control group to the treatment group suggests that, at least for restaurants, treated restaurants are fundamentally different from other restaurants. As a result the restaurant results are less compelling than the hotel results.

Another limitation of the matching approach is that one of the (untabulated) second stage results for the matched sample version of Table 5-the results where positive and negative treatment enter separately_-was noisy. The point estimates of positive and negative treatment effects were precisely estimated, and of the same size and approximate magnitude as in Table 5, but the t-test on the sum of the coefficients was not distinguishable from zero at the five percent level for the hotel sample, probably because the sample size in the matched sample regressions were much smaller than in the full sample. Thus, we cannot rule out the possibility that stock effects related to collocation are driven in part by selection effects. In other words, stock effects may not be the key source of intra-firm spillovers-the causal effect of collocation on performance. While this ambiguity does not contradict the evidence in support of our conceptual thrust, it would be nicer if we knew whether the magnitude of the stock effects remained after adjusting for selection effects. 
Finally, another limitation of this research is that we can only offer qualified statements about the mechanisms by which intra-firm spillovers obtain. From our interviews we expect that collocation leads to informal and formal knowledge sharing between proximate managers, however, we do not observe such effects directly. Rather we infer this kind of behavior from performance patterns in the data. As an extension of this work we explored potential mechanisms that might support the anecdotes we heard from managers, by examining marginal effects that might give some additional insight into how intra-firm collocation relates to performance at a more micro level. Specifically, in untabulated results, we studied how the interaction between establishment age and collocation, and local competitors' productivity and collocation influenced productivity. The idea for studying these two interaction effects was that older establishments would be more rigid (Rawley 2010), and therefore less willing to learn from experiments by new establishments, while new establishments in high-productivity markets might capture, and reflect back, more valuable local knowledge. While both effects were sometimes statistically and economically significant and in the direction expected-the benefits of collocation were far less pronounced in older establishments, and more pronounced for establishments with high-productivity competitors - neither was robust to all of our specifications. Thus, we leave open a promising opportunity to future scholars in the area to try to understand more precisely how intra-firm spillovers obtain.

\section{CONCLUSION}

Location choice is a central component of strategy for multi-unit firms. In particular, collocation can have large effects on how establishments operate and perform. In this paper we ask: (i) whether collocation has a causal effect on local within-firm performance; in other words, 
whether there are intra-firm spillovers associated with collocation; and (ii) how "stock" effects of collocation, such as one-time knowledge transference, compares to recurring "flow" effects due to ongoing resource sharing. We examine these issues using microdata from two large and economically important industries where multiunit firms are prevalent: the U.S. hotel and restaurant industries from 1977-2007.

The results suggest collocation causes economically and statistically meaningful positive within-firm performance effects, for both new and incumbent establishments. Stock benefits are found to be at least as large as the flow benefits of collocation, though the latter have received far more attention in the literature on collocation. The results are consistent with examples from hotel industry executives of how best practices diffuse locally within their organizations. Taken together the evidence suggests collocation helps new establishments learn from existing establishments' experience, and helps existing establishments learn from new establishments' experiments. Existing establishments transfer location-specific knowledge from new establishments, and new establishments experiment with new approaches and techniques that can be transferred back to existing establishments.

The findings have implications for both research and practice. For firms, this research suggests that a firm's collocation strategy hinges on their ability to encourage knowledge sharing across local organizations. For scholars, this paper represents a step toward unpacking collocation effects, allowing one to compare the relative importance of the drivers of collocation costs and benefits. However, many questions remain about why flow effects vary and when positive effects outweigh negative effects. Moreover, connecting stock and flow effects to micro mechanisms, particularly as those highlighted in the extant literature, would seem to be a fascinating research agenda. 


\section{REFERENCES}

Alcacer, Juan. 2006. Location Choices Across the Value Chain: How Activity and Capability Influence Collocation. Management Science 52(10): 1457-1471.

Allen, T. J. 1984. Managing the flow of technology: Technology transfer and the dissemination of technological information within the $R \& D$ organization. MIT Press Books, 1.

Baum, Joel A.C. 1995. The Changing Basis of Competition in Organizational Populations: the Manhattan Hotel Industry, 1898-1900. Social Forces 74(1): 177-204.

Baum, Joel A.C., and Heather A. Haveman. 1997. Love Thy Neighbor? Differentiation and Agglomeration in the Manhattan Hotel Indutry, 1898-1990. Administrative Science Quarterly 42(2): 304-338.

Baum, Joel A.C., and Paul Ingram. 1988. Survival-enhancing Learning in the Manhattan Hotel Industry, 1898-1980. Management Science 44(7): 996-1016.

Bennett, Victor M., Robert Seamans and Feng Zhu. Forthcoming. Cannibalization and option value effects of secondary markets: Evidence from the US concert industry. Strategic Management Journal.

Brandenburger A., \& Stuart, H. 2007. Biform games. Management Science, 53: 537-549.

Bresman, Henrik, Julian Birkinshaw, and Robert Nobel. "Knowledge transfer in international acquisitions." Journal of international business studies (1999): 439-462.

Chung, Wilbur and Arturs Kalnins. 2001. Agglomeration Effects and Performance: A Test of the Texas Lodging Industry. Strategic Management Journal 22(1): 969-988.

Darr E, Linda Argote and D. Epple. 1995. The Acquisition, Transfer and Depreciation of Knowledge in Service Organizations: Productivity in Franchises. Management Science 41(11): 1750-1762.

Eeckhout J, Jovanovic B. 2002. Knowledge Spillovers and Inequality. American Economic Review 92(5):1290-1307.

Ellison, Glen, Edward Glaeser and William Kerr. 2010. What Causes Industry Agglomeration? Evidence from Coagglomeration Patterns. The American Economic Review 100(3): 1195-1213.

Ethiraj, S. K., Levinthal, D., \& Roy, R. R. 2008. The dual role of modularity: innovation and imitation. Management Science 54(5), 939-955.

Giroud, Xavier. 2013. Proximity and Investment: Evidence from Plant-Level Data. Quarterly Journal of Economics, 128 (2):861-915. 
Gupta, A. K., \& Govindarajan, V. 1986. Resource sharing among SBUs: Strategic antecedents and administrative implications. Academy of Management journal, 29(4), 695-714.

Gupta, A. K., \& Govindarajan, V. 2000. Knowledge flows within multinational corporations. Strategic management journal, 21(4), 473-496.

Iacus, Stefano M., Gary King, and Giuseppe Porro. 2011. Multivariate Matching Methods That are Monotonic Imbalance Bounding. Journal of the American Statistical Association 106 (493): 345-361.

Iacus, Stefano M., Gary King, and Giuseppe Porro. 2012. Causal Inference without Balance Checking: Coarsened Exact Matching. Political Analysis 20 (1): 1-24.

Jaffe, Adam B., Manuel Trajenberg, and Rebecca Henderson. 1993. Geographic Localization of Knowledge Spillovers as Evidenced by Patent Citations. Quarterly Journal of Economics 108(3): 577-598.

Jin, G. Z., \& Leslie, P. 2009. Reputational incentives for restaurant hygiene. American Economic Journal: Microeconomics, 1(1), 237-267.

Kalnins, Arturs. 2004. An Empirical Analysis of Territorial Encroachment in Franchised and Company-owned Branded Chains. Marketing Science 23(4): 476-489.

Kalnins, Arturs, and Wilber Chung. 2004. Resource-seeking Agglomeration: A study of Market Entry in the Lodging Industry. Strategic Management Journal 25(7): 689-699.

Kalnins, Arturs, and Francine Lafontaine. 2014. Multi-unit Ownership in Franchising: Evidence from the Fast Food Industry in Texas. RAND Journal of Economics 35(4): 747-761.

Kalnins, Arturs, and Kyle J. Mayer. 2004. Relationships and hybrid contracts: An analysis of contract choice in information technology. Journal of Law, Economics, and Organization 20.1: 207-229.

Knott AM, Posen HE, Wu B. 2009. Spillover Asymmetry and Why It Matters. Management Science 55(3):373-388.

Lu, Susan F., and Gerard J. Wedig. 2013. Clustering, Agency Costs and Operating Efficiency: Evidence from Nursing Home Chains." Management Science 59(3): 677-694.

Marshall, A. 1920/1890. Principles of Economics. Macmillan Publishers: London, England

McCann, Brian T., and Govert Vroom. 2010. Pricing Response to Entry and Agglomeration Effects. Strategic Management Journal 31(3): 284-305.

Mowery, David C., Joanne E. Oxley, and Brian S. Silverman. 1996. Strategic alliances and interfirm knowledge transfer. Strategic management journal 17 (2): 77-91. 
Pancras, J., Sriram, S., and Kumar, V. 2012. Empirical investigation of retail expansion and cannibalization in a dynamic environment. Management Science 58(11), 2001-2018.

Posen HE and Chen JS. 2013. An Advantage of Newness: Vicarious Learning Despite Limited Absorptive Capacity. Organization Science 24(6): 1701-1716.

Quelch J. 2008. Starbucks' lessons for premium brands. HBS Working Knowledge (July 9), http://hbswk.hbs.edu/item/5973.html.

Rawley E. 2010. Diversification, coordination costs, and organizational rigidity: evidence from microdata. Strategic Management Journal 31(8): 873-891.

Ryall, M. D. 2009. Causal ambiguity, complexity, and capability-based advantage. Management Science, 55(3), 389-403.

Saxenian R. 1994. Regional Advantage: Culture and Competition in Silicon Valley and Route 128 Cambridge Massachusetts and London. Harvard University Press: Cambridge, MA.

Shaver, J. Myles, and Fredrick Flyer. 2000. Agglomeration economies, firm heterogeneity, and foreign direct investment in the United States. Strategic Management Journal 21(12): 11751194.

Williamson, O. E. 2005. The economics of governance. American Economic Review, 1-18.

Zhou YM. 2011. Synergy, coordination costs, and diversification choices. Strategic Management Journal 32(6): 624-639. 
Figure 1: Stock and flow effects arising from inter-firm and intra-firm collocation

\begin{tabular}{|c|c|c|}
\hline & Inter-firm & Intra-firm \\
\hline Flow & $\begin{array}{l}\text { Benefits: Classic Marshallian } \\
\text { agglomeration externalities, } \\
\text { including complementary supply } \\
\text { and demand } \\
\text { Costs: Competition }\end{array}$ & $\begin{array}{l}\text { Benefits: Economies of scale in } \\
\text { procurement, reputation building, } \\
\text { enhanced monitoring, ongoing } \\
\text { learning } \\
\text { Costs: Cannibalization }\end{array}$ \\
\hline Stock & $\begin{array}{l}\text { Benefits: One time knowledge } \\
\text { spillovers leaked from one firm to } \\
\text { another } \\
\text { Costs: Costly investments to imitate } \\
\text { or deter rivals }\end{array}$ & $\begin{array}{l}\text { Benefits: One time knowledge } \\
\text { "spillovers" shared between } \\
\text { business units owned by the same } \\
\text { parent firm } \\
\text { Costs: Internal politicking, } \\
\text { bureaucracy }\end{array}$ \\
\hline
\end{tabular}


Table 1: Summary statistics for incumbent dataset

\begin{tabular}{|c|c|c|c|c|}
\hline & \multicolumn{2}{|c|}{$\begin{array}{c}\text { Hotels } \\
(\mathrm{n}=180,583)\end{array}$} & \multicolumn{2}{|c|}{$\begin{array}{l}\text { Restaurants } \\
(\mathrm{n}=856,699)\end{array}$} \\
\hline & Mean & $\underline{\operatorname{Stdv}}$ & Mean & $\underline{\text { Stdv }}$ \\
\hline Sales $(\$ 000)$ & 906 & 4,913 & 725 & 940 \\
\hline Log establishments jgt $_{\text {. }}$ & 1.64 & 1.35 & 0.67 & 1.16 \\
\hline Positive treatment & 0.02 & 0.15 & 0.07 & 0.25 \\
\hline Negative treatment & 0.01 & 0.12 & 0.06 & 0.23 \\
\hline Payroll (\$000) & 254 & 1,445 & 203 & 307 \\
\hline Age (years) & 6.0 & 6.5 & 6.5 & 6.8 \\
\hline Log establishments $_{\mathrm{gt}}$ & 5.39 & 1.00 & 7.44 & 1.20 \\
\hline MSA LFP $_{-i, g t}$ & 0.00 & 0.10 & -0.02 & 0.06 \\
\hline $\log _{\text {establishments }}{ }_{\mathrm{j}, \mathrm{g}, \mathrm{t}}$ & 0.61 & 1.57 & 1.18 & 2.24 \\
\hline Year & 1994 & 10 & 1992 & 9 \\
\hline
\end{tabular}

Table 2: Summary statistics for entrant dataset

\begin{tabular}{|lcccc|}
\hline & \multicolumn{2}{c}{ Hotels } & \multicolumn{2}{c|}{ Restaurants } \\
& $\underline{\text { Mean }}$ & $\underline{\text { Stdv }}$ & $\underline{\text { Mean }}$ & $\underline{\text { Stdv }}$ \\
Sales $(\$ 000)$ & 811 & 4,661 & 668 & 934 \\
Collocated entrant dummy & 0.06 & 0.23 & 0.13 & 0.33 \\
Payroll (\$000) & 227 & 1,373 & 187 & 307 \\
Age (years) & 4.2 & 6.0 & 4.0 & 6.2 \\
Log establishments & 5.39 & 1.00 & 7.44 & 1.18 \\
MSA LFP & 0.00 & 0.10 & -0.01 & 0.06 \\
Log establishments & 0.50 & 1.42 & 1.11 & 2.16 \\
Year & 1994 & 10 & 1992 & 9 \\
\hline
\end{tabular}


Table 3: Baseline collocation results for incumbent establishments

\begin{tabular}{|c|c|c|c|c|}
\hline \multirow{3}{*}{$\begin{array}{l}\text { Dep var }=\log \text { sales } \\
\text { Log establishments } \text { jgt }_{\text {f }}\end{array}$} & \multicolumn{2}{|c|}{ Hotels } & \multicolumn{2}{|c|}{ Restaurants } \\
\hline & (1) & $(2)$ & (3) & (4) \\
\hline & $\begin{array}{c}0.024^{*} \\
(0.005)\end{array}$ & $\begin{array}{l}0.021^{*} \\
(0.004)\end{array}$ & $\begin{array}{c}0.008^{*} \\
(0.000)\end{array}$ & $\begin{array}{c}0.011^{*} \\
(0.000)\end{array}$ \\
\hline Log payroll & $\begin{array}{l}0.72^{*} \\
(0.00)\end{array}$ & $\begin{array}{l}0.83^{*} \\
(0.00)\end{array}$ & $\begin{array}{l}0.69^{*} \\
(0.00)\end{array}$ & $\begin{array}{l}0.70^{*} \\
(0.00)\end{array}$ \\
\hline Log age & & $\begin{array}{l}0.01^{*} \\
(0.00)\end{array}$ & & $\begin{array}{l}0.00^{*} \\
(0.00)\end{array}$ \\
\hline Log establishments $_{\mathrm{gt}}$ & & $\begin{array}{l}-0.01^{*} \\
(0.00)\end{array}$ & & $\begin{array}{l}-0.01^{*} \\
(0.00)\end{array}$ \\
\hline MSA LFP $_{-i, g t}$ & & $\begin{array}{l}0.08^{*} \\
(0.01)\end{array}$ & & $\begin{array}{l}0.24^{*} \\
(0.01)\end{array}$ \\
\hline Log establishments $_{\mathrm{j}, \mathrm{g}, \mathrm{t}}$ & & $\begin{array}{l}-0.00 \\
(0.00)\end{array}$ & & $\begin{array}{l}0.00^{*} \\
(0.00)\end{array}$ \\
\hline Establishment fixed effects & Y & Y & Y & Y \\
\hline Year fixed effects & Y & Y & $\mathrm{Y}$ & Y \\
\hline Ownership change dummy & $\mathrm{N}$ & $\mathrm{Y}$ & $\mathrm{N}$ & Y \\
\hline Firm LFP dummies (quartiles) & $\mathrm{N}$ & $\mathrm{Y}$ & $\mathrm{N}$ & Y \\
\hline MSA-Year fixed effects & $\mathrm{N}$ & Y & $\mathrm{N}$ & Y \\
\hline Constant & Y & Y & Y & Y \\
\hline $\mathrm{N}$ & 180,583 & 180,583 & 856,699 & 856,699 \\
\hline Adjusted $\mathrm{R}^{2}$ & 0.91 & 0.95 & 0.87 & 0.88 \\
\hline
\end{tabular}


Table 4: Collocation results for new establishments

\begin{tabular}{|c|c|c|c|c|}
\hline \multirow{3}{*}{$\begin{array}{l}\text { Dep var = log sales } \\
\text { Collocated entrant }\end{array}$} & \multicolumn{2}{|c|}{ Hotels } & \multicolumn{2}{|c|}{ Restaurants } \\
\hline & (1) & (2) & (3) & (4) \\
\hline & $\begin{array}{l}0.041^{*} \\
(0.004)\end{array}$ & $\begin{array}{c}0.024^{*} \\
(0.006)\end{array}$ & $\begin{array}{c}0.038^{*} \\
(0.001)\end{array}$ & $\begin{array}{c}0.020^{*} \\
(0.004)\end{array}$ \\
\hline Log payroll & $\begin{array}{l}0.926^{*} \\
(0.001)\end{array}$ & $\begin{array}{l}0.878^{*} \\
(0.004)\end{array}$ & $\begin{array}{c}0.757^{*} \\
(0.000)\end{array}$ & $\begin{array}{c}0.769^{*} \\
(0.005)\end{array}$ \\
\hline Log age & $\begin{array}{l}-0.005^{*} \\
(0.001)\end{array}$ & $\begin{array}{l}-0.001^{*} \\
(0.002)\end{array}$ & $\begin{array}{l}-0.005^{*} \\
(0.000)\end{array}$ & $\begin{array}{c}0.004^{*} \\
(0.001)\end{array}$ \\
\hline Log establishments $_{\mathrm{gt}}$ & $\begin{array}{l}0.005^{*} \\
(0.001)\end{array}$ & $\begin{array}{l}0.010^{*} \\
(0.002)\end{array}$ & $\begin{array}{l}-0.005^{*} \\
(0.000)\end{array}$ & $\begin{array}{l}-0.008^{*} \\
(0.001)\end{array}$ \\
\hline MSA LFP $_{-i, g t}$ & $\begin{array}{l}0.066^{*} \\
(0.007)\end{array}$ & $\begin{array}{c}0.057^{*} \\
(0.013)\end{array}$ & $\begin{array}{c}0.434^{*} \\
(0.008)\end{array}$ & $\begin{array}{c}0.209^{*} \\
(0.015)\end{array}$ \\
\hline $\log _{\text {establishments }}{ }_{\mathrm{j}, \mathrm{g}, \mathrm{t}}$ & $\begin{array}{l}0.014^{*} \\
(0.001)\end{array}$ & $\begin{array}{l}0.021^{*} \\
(0.009)\end{array}$ & $\begin{array}{c}0.004^{*} \\
(0.000)\end{array}$ & $\begin{array}{c}0.005 \\
(0.006)\end{array}$ \\
\hline Firm fixed effects & $\mathrm{N}$ & $\mathrm{Y}$ & $\mathrm{N}$ & $\mathrm{Y}$ \\
\hline Year fixed effects & Y & $\mathrm{Y}$ & Y & Y \\
\hline Ownership change dummy & Y & Y & Y & Y \\
\hline Firm LFP dummies (quartiles) & Y & $\mathrm{Y}$ & Y & Y \\
\hline Constant & $\mathrm{Y}$ & $\mathrm{Y}$ & $\mathrm{Y}$ & $\mathrm{Y}$ \\
\hline $\mathrm{N}$ & 261,906 & 261,906 & $1,459,118$ & $1,459,118$ \\
\hline Adjusted $\mathrm{R}^{2}$ & 0.95 & 0.95 & 0.87 & 0.88 \\
\hline
\end{tabular}


Table 5: Stock and flow effects of collocation

\begin{tabular}{|c|c|c|c|c|}
\hline \multirow[t]{2}{*}{ Dep var $=\log$ sales } & \multicolumn{2}{|c|}{ Hotels } & \multicolumn{2}{|c|}{ Restaurants } \\
\hline & (1) & (2) & (3) & (4) \\
\hline Positive treatment & $\begin{array}{c}0.033^{*} \\
(0.004)\end{array}$ & $\begin{array}{l}0.033^{*} \\
(0.004)\end{array}$ & $\begin{array}{c}0.028^{*} \\
(0.001)\end{array}$ & $\begin{array}{c}0.028^{*} \\
(0.001)\end{array}$ \\
\hline Negative treatment & $\begin{array}{l}-0.016 * \\
(0.006)\end{array}$ & $\begin{array}{l}-0.014^{*} \\
(0.006)\end{array}$ & $\begin{array}{c}0.011^{*} \\
(0.001)\end{array}$ & $\begin{array}{c}0.011^{*} \\
(0.001)\end{array}$ \\
\hline Log payroll & $\begin{array}{l}0.831^{*} \\
(0.003)\end{array}$ & $\begin{array}{l}0.829^{*} \\
(0.003)\end{array}$ & $\begin{array}{c}0.697^{*} \\
(0.001)\end{array}$ & $\begin{array}{c}0.697^{*} \\
(0.001)\end{array}$ \\
\hline Log age & $\begin{array}{c}0.005^{*} \\
(0.001)\end{array}$ & $\begin{array}{l}0.006^{*} \\
(0.001)\end{array}$ & $\begin{array}{c}0.000 \\
(0.001)\end{array}$ & $\begin{array}{l}0.000 \\
(0.01)\end{array}$ \\
\hline Log establishments $_{\mathrm{gt}}$ & $\begin{array}{l}-0.003 \\
(0.004)\end{array}$ & $\begin{array}{l}-0.011^{*} \\
(0.004)\end{array}$ & $\begin{array}{l}-0.007^{*} \\
(0.002)\end{array}$ & $\begin{array}{l}-0.004 \\
(0.002)\end{array}$ \\
\hline MSA LFP $_{-i, \mathrm{gt}}$ & $\begin{array}{l}0.064^{*} \\
(0.009)\end{array}$ & $\begin{array}{c}0.081^{*} \\
(0.010)\end{array}$ & $\begin{array}{c}0.242^{*} \\
(0.011)\end{array}$ & $\begin{array}{c}0.162^{*} \\
(0.012)\end{array}$ \\
\hline $\log _{\text {establishments }} \mathrm{j,g,t}$ & $\begin{array}{c}0.001 \\
(0.002)\end{array}$ & $\begin{array}{l}-0.002 \\
(0.002)\end{array}$ & $\begin{array}{c}0.004^{*} \\
(0.001)\end{array}$ & $\begin{array}{c}0.004^{*} \\
(0.001)\end{array}$ \\
\hline Establishment fixed effects & Y & Y & Y & Y \\
\hline Year fixed effects & Y & Y & Y & Y \\
\hline Ownership change dummy & Y & Y & Y & Y \\
\hline Firm LFP dummies (quartiles) & Y & Y & Y & Y \\
\hline MSA-Year fixed effects & $\mathrm{N}$ & Y & $\mathrm{N}$ & Y \\
\hline Constant & $\mathrm{Y}$ & $\mathrm{Y}$ & $\mathrm{Y}$ & $\mathrm{Y}$ \\
\hline $\mathrm{N}$ & 180,583 & 180,583 & 856,699 & 856,699 \\
\hline Adjusted $\mathrm{R}^{2}$ & 0.91 & 0.95 & 0.87 & 0.87 \\
\hline $\begin{array}{l}\text { Stock effect }=\text { positive treat } \\
+ \text { negative treat }\end{array}$ & $\begin{array}{c}0.017^{*} \\
(0.008)\end{array}$ & $\begin{array}{c}0.018^{*} \\
(0.008)\end{array}$ & $\begin{array}{c}0.039^{*} \\
(0.002)\end{array}$ & $\begin{array}{c}0.039^{*} \\
(0.002)\end{array}$ \\
\hline
\end{tabular}


Table 6: Propensity score matching for hotels sample

\begin{tabular}{|c|c|c|}
\hline $\begin{array}{l}\text { All variables are lagged } \\
\text { one period }\end{array}$ & $\begin{array}{l}\text { t-tests before } \\
\text { matching }\end{array}$ & $\begin{array}{c}\mathrm{t} \text {-tests after } \\
\text { matching }\end{array}$ \\
\hline & (1) & (2) \\
\hline Log sales & $+^{*}$ & + \\
\hline Log establishments $_{\text {jgt }}$ & $+*$ & $+^{*}$ \\
\hline Log payroll & $t^{*}$ & + \\
\hline Log age & $-^{+}$ & - \\
\hline Log establishments $_{\mathrm{gt}}$ & $+^{*}$ & + \\
\hline MSA LFP $_{-i, g t}$ & $+^{*}$ & $+^{+}$ \\
\hline Log establishments $_{\mathrm{j}, \mathrm{g}, \mathrm{t}}$ & $+^{*}$ & - \\
\hline Firm LFP & $t^{*}$ & + \\
\hline Date & $-^{*}$ & + \\
\hline
\end{tabular}


Table 7: Matched sample analysis

\begin{tabular}{|c|c|c|}
\hline Dep var $=\log$ sales & $\begin{array}{l}\text { Hotels } \\
\text { (1) }\end{array}$ & $\begin{array}{c}\text { Restaurants } \\
\text { (2) }\end{array}$ \\
\hline Log establishments $_{\text {jgt }}$ & $\begin{array}{c}0.021^{*} \\
(0.004)\end{array}$ & $\begin{array}{c}0.019^{*} \\
(0.006)\end{array}$ \\
\hline Log payroll & $\begin{array}{c}0.940^{*} \\
(0.002)\end{array}$ & $\begin{array}{c}0.852^{*} \\
(0.016)\end{array}$ \\
\hline Log age & $\begin{array}{l}0.034^{*} \\
(0.006)\end{array}$ & $\begin{array}{c}0.007^{*} \\
(0.002)\end{array}$ \\
\hline Log establishments $_{\mathrm{gt}}$ & $\begin{array}{c}-0.002 \\
(0.021)\end{array}$ & $\begin{array}{l}-0.013^{*} \\
(0.006)\end{array}$ \\
\hline MSA LFP $_{-i, g t}$ & $\begin{array}{l}0.0144^{*} \\
(0.043)\end{array}$ & $\begin{array}{c}0.233^{*} \\
(0.044)\end{array}$ \\
\hline $\log _{\text {establishments }}{ }_{\mathrm{j}, \mathrm{g}, \mathrm{t}}$ & $\begin{array}{c}0.002 \\
(0.004)\end{array}$ & $\begin{array}{c}0.004^{*} \\
(0.002)\end{array}$ \\
\hline Establishment fixed effects & $\mathrm{Y}$ & $\mathrm{Y}$ \\
\hline Year fixed effects & Y & Y \\
\hline Ownership change dummy & Y & Y \\
\hline Firm LFP dummies (quartiles) & Y & Y \\
\hline Constant & Y & Y \\
\hline $\mathrm{N}$ & 11,873 & 43,128 \\
\hline Adjusted $\mathrm{R}^{2}$ & 0.95 & 0.90 \\
\hline
\end{tabular}

